\title{
A Competing Failure Model based on Compound SSI, Random Shocks and Catastrophic Failure
}

\author{
Hongxia Chen \\ School of Reliability and System Engineering \\ Beihang University (BUAA) \\ Beijing, China, 010-82338236-807 \\ chxxm123@126.com
}

\author{
Yunxia Chen \\ School of Reliability and System Engineering \\ Beihang University (BUAA) \\ Beijing, China
}

\begin{abstract}
As products become increasingly complex, there are always more than one simple mechanisms that induce failure to the products, and failure modes are competing or dependent with each other rather than independent. Furthermore, the criterion to determine the failure state cannot be generalized to be a fixed value, thus probabilistic threshold is introduced. This paper proposed a probabilistic competing failure model based on catastrophic failure process and a dynamic compound SSI model, including cyclic operating stress and random shocks, where the cyclic stress can lead to the degradation of the strength. The independence of operating condition in each cycle is proved, thus the p.d.f. can be multiplied directly to achieve the joint probability. By assuming the linear relationship between the stress and the strength damage of each cycle, and Gaussian process to the stress and strength damage, the reliability of no strength degradation is developed through two parts with the random chocks which follows Poisson process. Usually, the catastrophic failure rate varies with the degradation of the strength. Therefore, a function of the strength is established to denote the dynamics of catastrophic failure rate. This model is demonstrated with a case of certain type of electronic product.
\end{abstract}

Keywords- competing failure; probabilistic failure threshold; SSI; compound stress; random shock; dependent

\begin{tabular}{|c|c|}
\hline \multicolumn{2}{|c|}{ Acronyms } \\
\hline i.i.d. & independent and identically distribution \\
\hline HPP & Homogeneous Poisson Process \\
\hline p.d.f & probability density function \\
\hline \multicolumn{2}{|c|}{ Notations } \\
\hline $\mathrm{S}_{i}$ & cyclic operating stress in the ith cycle \\
\hline $\mathrm{C}_{t}$ & random shock at time $t$ \\
\hline$x(t)$ & strength of product at time $t$ \\
\hline $\mathrm{Y}_{i}$ & damage to the strength in the ith cycle \\
\hline$\mu_{s}$ & Average of normal distribution of $\mathrm{S}_{i}$ \\
\hline$\sigma_{s}^{2}$ & Variance of normal distribution of $\mathrm{S}_{i}$ \\
\hline$\mu_{y}$ & Average of normal distribution of $Y_{i}$ \\
\hline$\sigma_{y}^{2}$ & Variance of normal distribution of $Y_{i}$ \\
\hline$\mu_{c}$ & Average of normal distribution of $C_{t}$ \\
\hline$\sigma_{c}^{2}$ & Variance of normal distribution of $C_{t}$ \\
\hline
\end{tabular}

\section{INTRODUCTION}

The modern products are complex than ever, thus the conventional reliability analysis can't satisfy the requirements of modern products. Usually, products have more than one failure mode, and they compete with each other. What's more, the criterion to determine the operation condition of products is tended to be a variable more than a fixed value, thus the probabilistic failure threshold is paid to more attention nowadays.

The failure criterion of SSI (stress- strength interference) model is that the strength of product or part of the product is smaller than the stress it bears. In general, the stress which the product bears is a random variable, and thus the failure criterion is uncertain, therefor, the SSI model is an important probabilistic failure threshold model.

Usually, the stress and strength can be assumed to be random variable respectively which follows a certain distribution. If the distribution is independent with time, then the model is called the static SSI model; on the contrary is the dynamic model. As an effect of the repeating stress, the strength of a product is degraded with time. Therefore, it is necessary for this paper to introduce the cyclic stress- strength interference model. That means the stress appears in a cycle of $\mathrm{T}$, and both the distribution of stress and strength vary with time.

Tang J.Y. etc. ${ }^{[1]}$ used Copula function and its related theory to establish both the static and dynamic SSI models, but they were applicable only to the continuous stress. Li X.Y. etc. ${ }^{[2]}$ researched the qualitative evaluation of reliability with respect to time by assuming the stress and the strength follow Brownian motion process, but they didn't take competing failure into consideration. Zhao J.Y. etc. ${ }^{[3,4]}$ proposed two models. One was the compound SSI model with continuous stress and random shocks, however, the strength was dependent with stress; the other one was the cyclic SSI model where the random shock was not in the model. Neither of them considered competing failure modes. More literatures ${ }^{[5,6]}$ researched the SSI model, but seldom involved competing failures.

The strength of the product is always dependent with the stress, and except for the strength degradation failure induced 
by the repeating stress, catastrophic failure occurs every now and then. Therefore, it is reasonable to study the competing failure model with compound SSI model and catastrophic failure. It is also a probabilistic failure threshold model.

This paper proposes a competing failure model based on catastrophic failure model and compound SSI model, which is including cyclic stress, depending strength, and random shocks. The organization of the paper is as following. Section II is the assumptions and basic proof. In section III, the modeling process is provided. A case was applied in section IV, and finally conclusions are given in section $\mathrm{V}$.

\section{ASSUMPTIONS AND BASIC PROOF}

\section{A. Assumptions}

(1) Product suffers the cyclic operating stress $S_{i}$, and the length of the cycle is T. Each $\mathrm{S}_{i} \stackrel{\text { i.i.d. }}{\sim} N\left(\mu_{s}, \sigma_{s}^{2}\right)$;

(2) Random shock $\mathrm{C}_{t}$ is HPP with $\lambda$, and $C_{t} \stackrel{\text { i.i.d. }}{\sim} N\left(\mu_{c}, \sigma_{c}^{2}\right)$, but it doesn't cause damage to the strength of the product;

(3) Each $S_{i}$ in the ith period causes linear damage $Y_{i}$ to the product, and their relationship is: $\mathrm{y}_{\mathrm{i}}=\mathrm{aS}_{\mathrm{i}}+b$, where $\mathrm{a}$ and $\mathrm{b}$ are constants;

(4) If the strength $x(t)$ is smaller than the sum of cyclic stress and random shock at time $t$, then the product occurs strength degradation failure;

(5) The strength affects the catastrophic failure rate $\lambda_{h}(t)$;

(6) The product is failed if either strength degradation failure or catastrophic failure occurs.

\section{B. Proof of Independence}

As the HPP is an independent process, we can assume that the product only suffers cyclic operating stress to simply the proof.

Title and Author Headings: Your first page should have the paper title, author(s) and affiliation(s) centered on the top of the page across both columns. According to the above assumption, each $S_{i}(i=1,2, \ldots)$ is independent with each other, and $\mathrm{y}_{\mathrm{i}}=\mathrm{aS}_{\mathrm{i}}+b$, we can get:

$$
\begin{aligned}
& \mathrm{P}\left\{\mathrm{x}_{0}-\mathrm{y}_{1} \geq \mathrm{S}_{2}, \mathrm{x}_{0} \geq \mathrm{S}_{1}\right\} \\
& =\mathrm{P}\left\{\mathrm{x}_{0}-\mathrm{y}_{1} \geq \mathrm{S}_{2} \mid \mathrm{x}_{0} \geq \mathrm{S}_{1}\right\} \\
& =\mathrm{P}\left\{\mathrm{x}_{0}-a \mathrm{~S}_{1}-b \geq \mathrm{S}_{2} \mid \mathrm{x}_{0} \geq \mathrm{S}_{1}\right\} P\left\{\mathrm{x}_{0} \geq \mathrm{S}_{1}\right\} \\
& =\mathrm{P}\left\{\mathrm{x}_{0}-\mathrm{y}_{1} \geq \mathrm{S}_{2}\right\} \mathrm{P}\left\{\mathrm{x}_{0} \geq \mathrm{S}_{1}\right\}
\end{aligned}
$$

Assume when $\mathrm{n}=\mathrm{m}$, exiting

$$
\begin{aligned}
& \mathrm{P}\left\{\mathrm{x}_{0}-\sum_{\mathrm{i}=1}^{\mathrm{m}-1} \mathrm{y}_{\mathrm{i}} \geq \mathrm{S}_{\mathrm{m}}, \mathrm{x}_{0}-\sum_{i=1}^{\mathrm{m}-2} \mathrm{y}_{\mathrm{i}} \geq \mathrm{S}_{\mathrm{m}-1}, \ldots, \mathrm{x}_{0} \geq \mathrm{S}_{1}\right\} \\
& =\mathrm{P}\left\{\mathrm{x}_{0}-\sum_{i=1}^{\mathrm{m}-1} \mathrm{y}_{\mathrm{i}} \geq \mathrm{S}_{\mathrm{m}}\right\} \ldots \mathrm{P}\left\{\mathrm{x}_{0} \geq \mathrm{S}_{1}\right\}
\end{aligned}
$$

When $\mathrm{n}=\mathrm{m}+1$, because $S_{i}(i=1,2, \ldots, m+1)$ is independent with each other, we can get

$$
\begin{aligned}
& \mathrm{P}\left\{\mathrm{x}_{0}-\sum_{i=1}^{m}\left(a S_{i}+b\right) \geq \mathrm{S}_{m+1} \mid \mathrm{x}_{0}-\sum_{i=1}^{\mathrm{m}-1} \mathrm{y}_{\mathrm{i}} \geq \mathrm{S}_{\mathrm{m}}, \ldots, \mathrm{x}_{0} \geq \mathrm{S}_{1}\right\} \\
& =\mathrm{P}\left\{\mathrm{x}_{0}-\sum_{i=1}^{m}\left(a S_{i}+b\right) \geq \mathrm{S}_{m+1}\right\}
\end{aligned}
$$

Therefore,

$$
\begin{aligned}
& \mathrm{P}\left\{\mathrm{x}_{0}-\sum_{i=1}^{m} \mathrm{y}_{\mathrm{i}} \geq \mathrm{S}_{m+1}, \quad \mathrm{x}_{0}-\sum_{i=1}^{m-1} \mathrm{y}_{\mathrm{i}} \geq \mathrm{S}_{m}, \ldots, \mathrm{x}_{0} \geq \mathrm{S}_{1}\right\} \\
& =\mathrm{P}\left\{\mathrm{x}_{0}-\sum_{i=1}^{m} \mathrm{y}_{\mathrm{i}} \geq \mathrm{S}_{m+1} \mid \mathrm{x}_{0}-\sum_{i=1}^{\mathrm{m}-1} \mathrm{y}_{\mathrm{i}} \geq \mathrm{S}_{\mathrm{m}}, \ldots, \mathrm{x}_{0} \geq \mathrm{S}_{1}\right\} \\
& \cdot \mathrm{P}\left\{\mathrm{x}_{0}-\sum_{i=1}^{\mathrm{m}-1} \mathrm{y}_{\mathrm{i}} \geq \mathrm{S}_{\mathrm{m}}, \ldots, \mathrm{x}_{0} \geq \mathrm{S}_{1}\right\} \\
& =\mathrm{P}\left\{\mathrm{x}_{0}-\sum_{i=1}^{m}\left(a S_{i}+b\right) \geq \mathrm{S}_{m+1} \mid \mathrm{x}_{0}-\sum_{i=1}^{\mathrm{m}-1} \mathrm{y}_{\mathrm{i}} \geq \mathrm{S}_{\mathrm{m}}, \ldots, \mathrm{x}_{0} \geq \mathrm{S}_{1}\right\} \\
& \cdot \mathrm{P}\left\{\mathrm{x}_{0}-\sum_{i=1}^{\mathrm{m}-1} \mathrm{y}_{\mathrm{i}} \geq \mathrm{S}_{\mathrm{m}}, \ldots, \mathrm{x}_{0} \geq \mathrm{S}_{1}\right\} \\
& =\mathrm{P}\left\{\mathrm{x}_{0}-\sum_{i=1}^{m} \mathrm{y}_{\mathrm{i}} \geq \mathrm{S}_{m+1}\right\} \mathrm{P}\left\{\mathrm{x}_{0}-\sum_{i=1}^{\mathrm{m}-1} \mathrm{y}_{\mathrm{i}} \geq \mathrm{S}_{\mathrm{m}}, \ldots, \mathrm{x}_{0} \geq \mathrm{S}_{1}\right\} \\
& =\mathrm{P}\left\{\mathrm{x}_{0}-\sum_{i=1}^{m} \mathrm{y}_{\mathrm{i}} \geq \mathrm{S}_{m+1}\right\} \mathrm{P}\left\{\mathrm{x}_{0}-\sum_{i=1}^{\mathrm{m}-1} \mathrm{y}_{\mathrm{i}} \geq \mathrm{S}_{\mathrm{m}}\right\} \ldots \mathrm{P}\left\{\mathrm{x}_{0} \geq \mathrm{S}_{1}\right\}
\end{aligned}
$$

According to the method of induction,

$$
\begin{aligned}
& \mathrm{P}\left\{\mathrm{x}_{0}-\sum_{\mathrm{i}=1}^{\mathrm{n}-1} \mathrm{y}_{\mathrm{i}} \geq \mathrm{S}_{n}, \quad \mathrm{x}_{0}-\sum_{i=1}^{n-2} \mathrm{y}_{\mathrm{i}} \geq \mathrm{S}_{n-1}, \ldots, \mathrm{x}_{0} \geq \mathrm{S}_{1}\right\} \\
& =\mathrm{P}\left\{\mathrm{x}_{0}-\sum_{i=1}^{n-1} \mathrm{y}_{\mathrm{i}} \geq \mathrm{S}_{n}\right\} \ldots \mathrm{P}\left\{\mathrm{x}_{0} \geq \mathrm{S}_{1}\right\}
\end{aligned}
$$

Where $n=1,2,3 \ldots$, and that is to say, the working condition of product in different period is independent, and the joint probability can be achieved via multiplying the p.d.f. immediately.

\section{MODELING PROCESS}

As the catastrophic failure rate is dependent with strength degradation process, the reliability of the product can be written as:

$$
R(t)=R_{s}(t) R_{h}(t \mid x(t))
$$


where $R_{h}(t \mid x(t))$ is the probability of no catastrophic failure with the relationship between strength and catastrophic failure rate.

\section{A. Strength Degradation Process}

Firstly, the strength degradation process is analyzed. The probability of no strength degradation failure is

$\mathrm{R}_{s}(\mathrm{t})=\mathrm{P}\{x(\tau) \geq \mathrm{S}(\tau), \forall \tau \in[0, \mathrm{t}]\}$

The length of cycle is $\mathrm{T}$, thus the operating stress at time $t$ is $S_{i}(i=1,2,3, \ldots)$, where $i=\left[\frac{t}{T}\right]+1$. As the damage caused by each $S_{i}$ satisfies following relationship:

$$
\mathrm{y}_{\mathrm{i}}=\mathrm{aS}_{\mathrm{i}}+b
$$

where $\mathrm{S}_{i} \stackrel{\text { i.i.d. }}{\sim} N\left(\mu_{\mathrm{s}}, \sigma_{\mathrm{s}}^{2}\right)$, then $\mathrm{y}_{\mathrm{i}} \sim \mathrm{N}\left(\mathrm{a}_{\mathrm{s}}+b,\left(\mathrm{a \sigma}_{\mathrm{s}}\right)^{2}\right)$, thus the mean and variance of $y_{i}$ are:

$$
\mu_{\mathrm{y}}=\mathrm{a} \mu_{\mathrm{s}}+b, \quad \sigma_{\mathrm{y}}^{2}=\left(\mathrm{a} \sigma_{\mathrm{s}}\right)^{2}
$$

Both of them are limited values. When operating time is large enough, according to the central-limit theorem we can get

$$
\xi(\mathrm{n})=\frac{\sum_{i=1}^{n} y_{i}-n \mu_{y}}{\sqrt{n} \sigma_{y}} \sim \mathrm{N}(0,1)
$$

If the initial strength at $t=0$ is $x_{0}$, then after a period time of $t$, the strength degraded to

$$
x(t)=x_{0}-\sum_{i=1}^{[t / \mathrm{T}]-1} \mathrm{y}_{\mathrm{i}}
$$

Next, take the random shocks into consideration. As the arrival times $\{N(t)=0,1,2, \ldots\} \sim H P P$ with rate $\lambda$, so

$$
\begin{aligned}
& P\{N(\Delta t)=1\}=\lambda \Delta t+o(\Delta t) \\
& P\{N(\Delta t)>1\}=o(\Delta t) \\
& P\{N(\Delta t)<1\}=1-\lambda \Delta t+o(\Delta t)
\end{aligned}
$$

According to the section I, the working condition of product in different period is independent. The probability of no strength failure during period $[0, t+\Delta t]$ is

$$
\begin{aligned}
& \mathrm{R}_{\mathrm{s}}(\mathrm{t}+\Delta \mathrm{t}) \\
& =\mathrm{P}\left\{x_{0}-\sum_{i=1}^{[\tau / T]-1} \mathrm{y}_{\mathrm{i}} \geq \mathrm{S}_{[\tau / T]}+\mathrm{C}_{\tau}, \forall \tau \in[0, \mathrm{t}+\Delta \mathrm{t}]\right\} \\
& =\mathrm{P}\left\{x_{0}-\sum_{i=1}^{[\tau / T]-1} \mathrm{y}_{\mathrm{i}} \geq \mathrm{S}_{[\tau / T]}+\mathrm{C}_{\tau}, \forall \tau \in[0, \mathrm{t}]\right\} \times \\
& \mathrm{P}\left\{x_{0}-\sum_{i=1}^{[\tau / T]-1} \mathrm{y}_{\mathrm{i}} \geq \mathrm{S}_{[\tau / T]}+\mathrm{C}_{\tau}, \forall \tau \in[\mathrm{t}, \mathrm{t}+\Delta \mathrm{t}]\right\} \\
& =\mathrm{R}_{\mathrm{s}}(\mathrm{t}) \mathrm{P}\left\{x_{0}-\sum_{i=1}^{[\tau / T]-1} \mathrm{y}_{\mathrm{i}} \geq \mathrm{S}_{[\tau / T]}+\mathrm{C}_{\tau}, \forall \tau \in[\mathrm{t}, \mathrm{t}+\Delta \mathrm{t}]\right\}
\end{aligned}
$$

While the latter function can be written as:

$$
\begin{aligned}
& \mathrm{P}\left\{x_{0}-\sum_{i=1}^{[\tau / T]-1} \mathrm{y}_{\mathrm{i}} \geq \mathrm{S}_{[\tau / T]}+\mathrm{C}_{\tau}, \forall \tau \in[\mathrm{t}, \mathrm{t}+\Delta \mathrm{t}]\right\} \\
& =1-\mathrm{P}\left\{x_{0}-\sum_{i=1}^{\left[\tau^{*} / T\right]-1} \mathrm{y}_{\mathrm{i}} \leq \mathrm{S}_{\left[\tau^{*} / T\right.}+\mathrm{C}_{\tau^{*}}, \exists \tau^{*} \in[\mathrm{t}, \mathrm{t}+\Delta \mathrm{t}]\right\} \\
& \cdot P\left\{\text { in }[\mathrm{t}, \mathrm{t}+\Delta \mathrm{t}] \mathrm{C}_{\tau^{*}} \text { occurs }\right\} \\
& -\mathrm{P}\left\{x_{0}-\sum_{i=1}^{\left[\tau^{*} / T\right]-1} \mathrm{y}_{\mathrm{i}} \leq \mathrm{S}_{\left[\tau^{*} / \mathrm{T}\right]}, \exists \tau^{*} \in[\mathrm{t}, \mathrm{t}+\Delta \mathrm{t}]\right\} \\
& \cdot P\left\{\text { in }[\mathrm{t}, \mathrm{t}+\Delta \mathrm{t}] \mathrm{C}_{\tau^{*}} \text { unoccurs }\right\}
\end{aligned}
$$

Through some transformer, (16) becomes:

$$
\begin{aligned}
& \frac{\mathrm{R}_{\mathrm{s}}(\mathrm{t}+\Delta \mathrm{t})-\mathrm{R}_{\mathrm{s}}(\mathrm{t})}{\Delta \mathrm{t}} \\
& =-\mathrm{R}_{\mathrm{S}}(\mathrm{t})\left(\mathrm{P}\left\{x_{0}-\sum_{i=1}^{\left[\tau^{*} / T\right]-1} \mathrm{y}_{\mathrm{i}} \leq \mathrm{S}_{\left[\tau^{*} / T\right]}+\mathrm{C}_{\tau}, \exists \tau^{*} \in[\mathrm{t}, \mathrm{t}+\Delta \mathrm{t}]\right\} \lambda\right. \\
& \left.+\mathrm{P}\left\{x_{0}-\sum_{i=1}^{\left[\tau^{*} / T\right]-1} \mathrm{y}_{\mathrm{i}} \leq \mathrm{S}_{\left[\tau^{*} / T\right]}, \exists \tau^{*} \in[\mathrm{t}, \mathrm{t}+\Delta \mathrm{t}]\right\}(1-\lambda)+\frac{o(\Delta \mathrm{t})}{\Delta \mathrm{t}}\right)
\end{aligned}
$$

When $\Delta t \rightarrow 0,(18)$ turns to:

$$
\begin{aligned}
& \frac{\mathrm{dR}_{\mathrm{s}}(\mathrm{t})}{\mathrm{dt}}=-\mathrm{R}_{\mathrm{s}}(\mathrm{t})\left(\mathrm{P}\left\{x_{0}-\sum_{i=1}^{[t / T]-1} \mathrm{y}_{\mathrm{i}} \leq \mathrm{S}_{[t / T]}+\mathrm{C}_{t}\right\} \lambda\right. \\
& \left.+\mathrm{P}\left\{x_{0}-\sum_{i=1}^{[t / T]-1} \mathrm{y}_{\mathrm{i}} \leq \mathrm{S}_{[t / T]}\right\}(1-\lambda)\right)
\end{aligned}
$$

Furthermore, 


$$
\begin{aligned}
& \mathrm{P}\left\{x_{0}-\sum_{i=1}^{[t / T]-1} \mathrm{y}_{\mathrm{i}} \leq \mathrm{S}_{[t / T]}+\mathrm{C}_{\mathrm{t}}\right\} \\
& =1-\mathrm{P}\left\{x_{0}-\sum_{i=1}^{[t / T]-1} \mathrm{y}_{\mathrm{i}} \geq \mathrm{S}_{[t / T]}+\mathrm{C}_{\mathrm{t}}\right\} \\
& =1-\mathrm{P}\left\{\frac{S[t / T]}{\sqrt{[t / T]-1} \sigma_{y}}+\frac{C_{t}}{\sqrt{[t / T]-1} \sigma_{y}}\right. \\
& \left.+\xi([t / T]-1) \leq \frac{x_{0}-([t / T]-1) \mu_{y}}{\sqrt{[t / T]-1} \sigma_{y}}\right\}
\end{aligned}
$$

As $C_{t} \stackrel{\text { i.i.d. }}{\sim} N\left(\mu_{c}, \sigma_{c}^{2}\right), \zeta(t)$ denotes

$\zeta(\mathrm{t})=\frac{C_{t}}{\sqrt{[t / T]-1} \sigma_{y}} \sim \mathrm{N}\left(\frac{\mu_{\mathrm{c}}}{\sqrt{[t / T]-1} \sigma_{y}}, \frac{\sigma_{\mathrm{c}}{ }^{2}}{([t / T]-1) \sigma_{y}^{2}}\right)$.

Then $\zeta(t)$ and $\xi(t)$ are independent, therefore,

$\varsigma(\mathrm{t})=\zeta(\mathrm{t})+\xi\left(\left[\frac{t}{T}\right]-1\right) \sim \mathrm{N}\left(\frac{\mu_{c}}{\sqrt{\left[\frac{t}{T}\right]-1 \sigma_{y}}}, \frac{\sigma_{c}^{2}}{\left(\left[\frac{t}{T}\right]-1\right) \sigma_{y}^{2}}+1\right)$

Let $\gamma(t)$ denotes $\frac{S_{[t / T]}}{\sqrt{[t / T]-1} \sigma_{y}}$, apparently, $\gamma(t)$ and $\varsigma(t)$ are independent, and their union distribution can be written as $\Psi(\mathrm{t})=\gamma(\mathrm{t}) *_{\mathrm{s}}(\mathrm{t})$

$$
\sim N\left(\frac{\mu_{c}+\mu_{s}}{\sqrt{[t / T]-1} \sigma_{y}}, \frac{\sigma_{c}^{2}+\sigma_{s}^{2}}{([t / T]-1) \sigma_{y}^{2}}+1\right)
$$

Similarly, $\gamma(t)$ and $\xi(t)$ are independent, thus we can denote $\Omega(\mathrm{t})=\gamma(\mathrm{t}) * \xi(\mathrm{t})$ as the union distribution of $\gamma(t)$ and $\xi(t)$. And

$\Omega(t) \sim N\left(\frac{\mu_{s}}{\sqrt{[t / T]-1} \sigma_{y}}, \frac{\sigma_{s}^{2}}{([t / T]-1) \sigma_{y}^{2}}+1\right)$

Therefore

$\mathrm{P}\left\{x_{0}-\sum_{i=1}^{[t / T]-1} \mathrm{y}_{\mathrm{i}} \leq \mathrm{S}_{[t / T]+1}+\mathrm{C}_{\mathrm{t}}\right\} \lambda+\mathrm{P}\left\{x_{0}-\sum_{i=1}^{[t / T]-1} \mathrm{y}_{\mathrm{i}} \leq \mathrm{S}_{[t / T]+1}\right\}(1-\lambda)$
$=\lambda\left[1-\Psi\left(\frac{x_{0}-([t / T]-1) \mu_{y}}{\sqrt{[t / T]-1} \sigma_{y}}\right)\right]+(1-\lambda)\left[1-\Omega\left(\frac{x_{0}-([t / T]-1) \mu_{y}}{\sqrt{[t / T]-1} \sigma_{y}}\right)\right]$

Eventually, we can get the probability of no strength degradation failure:

$$
\begin{aligned}
& \mathrm{R}_{\mathrm{s}}(\mathrm{t})=\exp \left(-\lambda \int_{0}^{\mathrm{t}}\left[1-\Psi\left(\frac{x_{0}-([\tau / T]-1) \mu_{y}}{\sqrt{[\tau / T]-1} \sigma_{y}}\right)\right] \mathrm{d} \tau\right. \\
& \left.-(1-\lambda) \int_{0}^{\mathrm{t}}\left[1-\Omega\left(\frac{x_{0}-([\tau / T]-1) \mu_{y}}{\sqrt{[\tau / T]-1} \sigma_{y}}\right)\right] \mathrm{d} \tau\right)
\end{aligned}
$$

\section{B. Catastrophic Failure and Final reliability}

As the catastrophic failure rate is $\lambda_{h}(t)=\lambda_{h}(x(t))$, then

$$
\begin{aligned}
& R_{h}(t)=\exp \left(-\int_{0}^{t} \lambda_{h}(t) d t\right) \\
& =\exp \left(-\int_{0}^{t} \lambda(x(t)) d t\right)
\end{aligned}
$$

If $\lambda(x(t))=\lambda_{0}+\sigma x(t)$, where $\lambda_{0}$ and $\sigma$ are constants, then

$R_{h}(t)=e^{-\int_{0}^{t} \lambda_{0}+\sigma x(t) d t}$

Through all above analysis, the final reliability of the product is

$$
\begin{aligned}
& \mathrm{R}(\mathrm{t})=\exp \left(-\lambda \int_{0}^{\mathrm{t}}\left[1-\Psi\left(\frac{x_{0}-([\tau / T]-1) \mu_{y}}{\sqrt{[\tau / T]-1} \sigma_{y}}\right)\right] \mathrm{d} \tau\right. \\
& \left.-(1-\lambda) \int_{0}^{\mathrm{t}}\left[1-\Omega\left(\frac{x_{0}-([\tau / T]-1) \mu_{y}}{\sqrt{[\tau / T]-1} \sigma_{y}}\right)\right] \mathrm{d} \tau\right) e^{-\int_{0}^{t} \lambda_{0}+\sigma x(t) d t}
\end{aligned}
$$

\section{CASE STUdy}

There is a certain type of electronic product which suffer the cyclic operating stress every 10 hours, and $S_{i} \sim N(10,1)$. The damage caused by each stress is $y_{i}=0.1 S_{i}+0.1$. In addition, the product also suffers random shocks which follow the HPP with $1 / \lambda=20$ hours, and the magnitude of the random shock $\mathrm{C}_{t} \sim \mathrm{N}(5,1)$. The initial strength of the product is $x_{0}=1000$.To simply the analysis, let $\sigma=0$, thus $\lambda(x(t))=0.0001$.

According to (9), $\mu_{y}=0.1 * 10+0.1=1.1$

$\sigma_{y}^{2}=(0.1 * 1)^{2}=0.1^{2}$.

It can be inferred that

$\Psi(t) \sim N\left(\frac{\mu_{c}+\mu_{s}}{\sqrt{[t / T]-1} \sigma_{y}}, \frac{\sigma_{c}{ }^{2}+\sigma_{s}^{2}}{([t / T]-1) \sigma_{y}^{2}}+1\right)$

$=N\left(\frac{150}{\sqrt{[t / T]-1}}, \frac{200}{([t / T]-1)}+1\right)$

And 


$$
\begin{aligned}
& \Omega(t) \sim N\left(\frac{\mu_{s}}{\sqrt{[t / T]-1} \sigma_{y}}, \frac{\sigma_{s}^{2}}{([t / T]-1) \sigma_{y}^{2}}+1\right) \\
& =N\left(\frac{100}{\sqrt{[t / T]-1}}, \frac{100}{([t / T]-1)}+1\right)
\end{aligned}
$$

Combine (26), the reliability is

$$
\begin{aligned}
& \mathrm{R}(\mathrm{t})=\exp \left(-0.05 \int_{0}^{\mathrm{t}}\left[1-\Psi\left(\frac{10000-([\tau / T]-1) * 11}{\sqrt{[\tau / T]-1}}\right)\right] \mathrm{d} \tau\right. \\
& \left.-(1-0.05) \int_{0}^{\mathrm{t}}\left[1-\Omega\left(\frac{100000-([\tau / T]-1) 110}{\sqrt{[\tau / T]-1}}\right)\right] \mathrm{d} \tau\right) e^{-0.0001 t}
\end{aligned}
$$

Fig. 1 shows the reliability curve of the product. As seem from the reliability curve, the reliability at $\mathrm{t}=500 \mathrm{hour}$ is close to 1 , and afterwards the reliability is reduced rapidly. If no failure happens before 2000 hour, then maintenance is necessary as the reliability degrades the fastest.



Figure 1. Reliablity curve

\section{CONCLUSIONS}

This paper proposed a competing failure model based on the dynamic compound SSI model and catastrophic failure process. The dynamic is shown on three aspects of this paper: the stress changes with time; the strength of product is degraded with the repeating of cyclic operating stress; the catastrophic failure rate is dependent with the degradation of strength. The dynamic model considered both multimechanism and probabilistic failure threshold. As a result to the electronic product case, the model is applicable efficient to the reliability engineering. It provides a new method to evaluate the reliability of products as well as a basis for the management and maintenance of products.

\section{REFERENCES}

[1] J.Y. Tang, Y.X. Zhao, and D.L. Song, "Static and dynamic models for reliability calculation of stress-strength interference," Journal of Southwest Jiaotong University, Vol. 45, 2010, pp.384-388.

[2] X.Y. Li and T.J. Jiang, "Quantitative evaluation of accelerated stress testing based on SSI," Journal of Beijing University of Aeronautics and Astronautics, Vol. 34, 2008, pp.1298-1302.

[3] Q. Sun, J.Y. Zhao, and J.L. Zhou, "Stress-strength interference reliability analysis considering stochastic multi-stress and strength aging degradation," Chinese Journal of Computational Mechanics, Vol. 24, 2007, pp.358-361

[4] Q. Sun., J.Y. Zhao, and J.L. Zhou, "Stress-strength interference reliability analysis considering cyclic stochastic stress and strength aging degradation," Journal of Applied Sciences, Vol. 24, 2006, pp.529-532.

[5] J. Xue, and K. Yang, "Upper \& lower bounds of stress-strength interference reliability with random strength-degradation," IEEE Trans. On Reliability," Vol. 42, 1997, pp.142-145

[6] W. Huang, G. A. Ronald, "A generalized SSI reliability model considering stochastic loading and strength aging degradation," IEEE Trans. On Reliability, Vol. 53, 2004, pp.77-82. 